\title{
ORIENTAÇÕES DE ENFERMAGEM NAS ADAPTAÇÕES FISIOLÓGICAS DA GESTAÇÃO*
}

\author{
Ricardo Saraiva Aguiar1, Maria Aparecida Batista de Araújo², Marli Aparecida Costa², \\ Nicoly Aguiar ${ }^{3}$
}

\begin{abstract}
RESUMO: Este estudo teve por objetivo analisar as orientações de enfermagem fornecidas às gestantes quanto às queixas clínicas mais frequentes durante a gravidez. Trata-se de um estudo descritivo e de abordagem qualitativa, realizado entre os meses de março e abril de 2011, com a participação de 14 gestantes cadastradas em uma unidade básica de saúde de Gurupi-Tocantins. Utilizouse um roteiro de entrevista semiestruturado e os resultados foram analisados por meio da análise de conteúdo. Os principais sintomas referidos foram náuseas, vômitos, edema e lombalgia; as orientações prestadas pelo enfermeiro na assistência pré-natal de baixo risco foram adequadas e possibilitaram compreensão, por parte das gestantes, da sintomatologia apresentada. Foram indicadas intervenções pertinentes às manifestações, apesar de não serem contempladas todas as intervenções recomendadas. DESCRITORES: Cuidado pré-natal; Enfermagem; Qualidade da assistência à saúde.
\end{abstract}

\section{NURSING GUIDANCE IN THE PHYSIOLOGICAL ADAPTATIONS OF PREGNANCY*}

ABSTRACT: This study aimed to analyze nursing guidance provided to pregnant women regarding the most frequent clinical complaints during pregnancy. It is a descriptive study with a qualitative approach, undertaken between March and April 2011, with the participation of 14 pregnant women registered in a Primary Health Care Center in Gurupi, in the state of Tocantins. A semi-structured interview script was used and the results being analyzed using content analysis. The principal symptoms mentioned were nausea, vomiting, edema and lower back pain; the guidance provided by the nurse in the pre-natal care for those at low risk was adequate and allowed the pregnant women to understand the symptoms experienced. Interventions relevant to the manifestations were indicated, in spite of the fact that not all the recommended interventions were covered. DESCRIPTORS: Pre-natal care; Nursing; Quality of the health care.

\section{ORIENTACIONES DE ENFERMERÍA EN LAS ADAPTACIONES FISIOLÓGICAS DE LA GESTACIÓN}

RESUMEN: Este estudio tuvo el objetivo de analizar las orientaciones de enfermería dadas a las gestantes acerca de las quejas clínicas más frecuentes durante la gravidez. Es un estudio descriptivo de abordaje cualitativo, realizado entre los meses de marzo y abril de 2011, con la participación de 14 gestantes registradas en una unidad básica de salud de Gurupi, Tocantins. Fue utilizado un guión de entrevista semiestructurado y los resultados fueron analizados por medio del análisis de contenido. Los principales síntomas mencionados fueron náuseas, vómitos, edema y lumbalgia; las orientaciones prestadas por el enfermero en la asistencia prenatal de poco riesgo fueron adecuadas y posibilitaron comprensión, por parte de las gestantes, de la sintomatología presentada. Fueron indicadas intervenciones pertinentes a las manifestaciones, a pesar de no se contemplar todas las intervenciones recomendadas.

DESCRIPTORES: Cuidado prenatal; Enfermería; Calidad da asistencia a la salud.

*Artigo elaborado a partir do trabalho de conclusão de curso "A percepção das gestantes em relação às orientações prestadas pelo enfermeiro durante o pré-natal de baixo risco" apresentado ao Centro Universitário UNIRG, em 2011.

${ }^{1}$ Enfermeiro da Secretaria de Estado da Saúde do Distrito Federal. Especialista em Saúde da Família.

${ }^{2}$ Enfermeira.

${ }^{3}$ Enfermeira. Especialista em Auditoria em Saúde. Professora e Coordenadora de Estágio do Curso de Graduação em Enfermagem do Centro Universitário - UNIRG. 


\section{INTRODUÇÃO}

A gestação é um evento fisiológico normal que traz várias modificações ao organismo materno que começam na primeira semana de gestação e continuam durante todo o período gestacional ${ }^{(1)}$. Essas modificações decorrem de intensa transformação como resposta às demandas próprias dessa fase. Nesse período, o corpo da mulher é constante e intensamente sensibilizado o que traduz uma série de desconfortos, expressa por sinais e sintomas, que variam dependendo da tolerância de cada mulher ao desconforto e da intensidade com que eles se apresentam $^{(2)}$.

Tais alterações advindas desse período necessitam de atenção qualificada por parte dos profissionais de saúde que devem identificar as adaptações, bem como suas consequências, já que estas podem tornar-se fontes de limitação para a mulher ${ }^{(3)}$.

Visando melhorar a qualidade de vida das gestantes neste período e evitar futuras complicações, maternas e neonatais, torna-se imprescindível uma assistência pré-natal de qualidade, com acompanhamento por equipe multidisciplinar assegurando, ao final da gestação, o nascimento de uma criança saudável e o bem-estar materno.

A consulta de enfermagem apresenta-se como um instrumento de suma importância no pré-natal, pois têm como finalidade garantir a extensão da cobertura e melhoria da qualidade pré-natal, principalmente por meio da introdução das ações preventivas e promocionais às gestantes. É requerido do profissional, além da competência técnica, sensibilidade para compreender o ser humano e o seu modo de vida, e habilidade de comunicação baseada na escuta e na ação dialógica ${ }^{(4)}$.

Dessa forma, há a necessidade de melhorar a qualidade das consultas de enfermagem, principalmente fortalecendo o acolhimento a fim de garantir a adesão ao pré-natal, pois o trabalho da Enfermagem está centrado no cuidado e tem como sujeito o cliente ${ }^{(5)}$. Baseado nisso, a importância deste estudo justifica-se pela necessidade do enfermeiro conhecer os principais desconfortos durante a gestação e as condutas adequadas a serem aplicadas no decorrer do pré-natal, tendo em vista que este profissional de enfermagem possui papel fundamental no cuidado das gestantes.

Nesse sentido, este estudo verificou quais orientações foram fornecidas às gestantes durante o pré-natal sobre as principais queixas clínicas durante a gravidez. Com isso, espera-se oferecer subsídios para melhorar a qualidade da assistência pré-natal oferecida.

\section{MÉTODO}

Trata-se de um estudo descritivo e de abordagem qualitativa avaliado e aprovado pelo parecer $n$. 0202/2010 do Comitê de Ética em Pesquisa do Centro Universitário UNIRG e autorizado pela Secretaria Municipal de Saúde de Gurupi-Tocantins. Todos os procedimentos metodológicos obedeceram aos padrões estabelecidos pela Resolução n. 196/1996 do Conselho Nacional de Saúde que trata das Normas de Pesquisa Envolvendo Seres Humanos.

O estudo foi realizado em uma Unidade Básica de Saúde (UBS) municipal entre os meses de março e abril de 2011. Gurupi está localizado na região sul do Estado do Tocantins e possui uma população de 76.765 habitantes.

Os participantes desta pesquisa constituíram-se de 14 gestantes que atenderam os seguintes critérios de inclusão: estar classificada como gestação de baixo risco; frequentando regularmente as consultas de enfermagem; na faixa etária de 19 a 40 anos de idade; e aceitar de livre e espontânea vontade participar da pesquisa, formalizando a participação por meio da assinatura do Termo de Consentimento Livre e Esclarecido, antes da realização das entrevistas.

$\mathrm{Na}$ coleta de dados, optou-se pelo emprego de entrevista semiestruturada na qual as entrevistadas responderam questões de identificação pessoal e também às questões abertas. Adotou-se a seguinte questão norteadora neste estudo: Quais orientações você recebeu da enfermeira? As entrevistas foram realizadas durante a visita domiciliar, após a autorização das gestantes. Para garantir o anonimato das participantes foram todas identificadas pela letra "M" e o respectivo número à ordem de sua entrevista.

O conteúdo das entrevistas foram gravados e transcritos fidedignamente; o processo de explicitação, sistematização e expressão do conteúdo das mensagens foi realizado por meio da proposta de Minayo ${ }^{(6)} \mathrm{em}$ três etapas realizadas em conformidade com três pólos cronológicos diferentes: pré-análise, exploração do material, tratamento dos resultados obtidos e interpretação.

\section{RESULTADOS}

Entre as 14 gestantes participantes, a maioria era casada ( $\mathrm{n}=11) ; 8$ tinham o ensino médio completo, quatro o ensino superior, uma o ensino médio incompleto e uma o ensino fundamental.

Verifica-se nos depoimentos das gestantes que as principais manifestações referidas foram as náuseas e 
vômitos como se observa nos depoimentos a seguir:

Senti náuseas e vômitos, mas a enfermeira nunca falou nada sobre as maneiras de evitar esses sintomas não [...] ela [enfermeira] falou sobre a azia somente que é devido ficar muito tempo sem comer. (M1)

Eu tive muito vômito no início da gestação, ai ela [enfermeira] disse que era para eu me alimentar de 3 em 3 horas, em pequenas porções e comer muita fruta também. (M6)

Foi nos primeiros meses da gestação que eu tive muito enjoo, mais ou menos até o quarto mês. A enfermeira disse para eu comer porque estava abaixo do peso, mas é difícil por causa do enjoo. (M8)

Como eu estava tendo muito enjoo ela me falou que não era para eu ficar muito tempo sem comer e era para cuidar mais da minha alimentação. Ela falou também para comer mais verduras e frutas, e também evitar comidas gordurosas, ainda mais eu que engravidei acima do peso. (M9)

Outra queixa relatada foi o edema:

Eu fiquei muito inchada, principalmente, quando ficava muito tempo em pé. A enfermeira me orientou direitinho sobre os cuidados que deveria ter devido o surgimento do edema. (M2)

Minhas pernas ficaram inchadas quando estava com 7 meses, ai a enfermeira disse para eu deitar do ladoesquerdo e elevar as pernas quando fosse deitar também. (M10)

A lombalgia foi referida por duas gestantes como se observa nos relatos a seguir:

Eu tive dores nas pernas, mas quando eu reclamei para a enfermeira, ela disse que era eu para colocar as pernas para cima. (M3)

Eu reclamei de dores na coluna e inchaço ai ela [enfermeira] recomendou que eu andasse um pouquinho. Ela falou também para comer de 3 em 3 horas porque senão eu posso ter náuseas e vômitos, mas nada de comer frituras ou muita massa. (M11)

Pode ocorrer dispneia quando a mulher se deita e a pressão do útero gravídico contra a veia cava inferior reduz o retorno venoso ao coração o que provoca alteração na função normal cardiopulmonar. Essa queixa foi relatada pelas gestante, como observa-se a seguir:

Eu sinto muita falta de ar, principalmente quando eu vou deitar. A enfermeira falou pra mim que é devido à compressão de uma veia que temos no abdome e que era para eu deitar do lado esquerdo. (M12)

A falta de ar começou quando a barriga estava já grande e ficava pior quando eu deitava. (M14)

Verificou-se ainda que outras orientações foram fornecidas pelo enfermeiro durante o pré-natal de baixo risco, como percebe-se nos relatos a seguir:

Ela [enfermeira] perguntou qual era o lado que eu deitava ai eu falei que era do lado direito, ai ela disse que era para eu deitar do lado esquerdo para melhorar a circulação e evitar deitar com a barriga para cima. (M4)

A enfermeira disse que tem que fazer caminhada, colocar as pernas para cima quando deitar e fazer massagem também. (M5)

Ela [enfermeira] disse que o aparecimento de sintomas são frequentes na gestação, mas se eu sentisse uma coisa mais séria era para procurar o posto de saúde. Sobre alimentação, ela disse que era para comer frutas, verduras e não comida muito pesada e nem muito tarde. (M7)

A enfermeira falou que quando eu deitasse era para eu sempre colocar os pés para cima. (M13)

\section{DISCUSSÃO}

O corpo da gestante passa por uma série de alterações que ocorrem devido a fatores hormonais e mecânicos envolvendo diversos aparelhos e sistemas ${ }^{(7)}$.

As alterações fisiológicas que a gravidez desencadeia são capazes de produzirem diversas manifestações no organismo da mulher que, podem ser percebidas como doenças pelas mulheres na maioria das vezes. Baseado nisso, cabe ao profissional de saúde orientar e interpretar corretamente essas situações de forma a não banalizar as queixas apresentadas ${ }^{(8)}$.

O surgimento destes sintomas nas mulheres grávidas requer mudança no estilo de vida e comportamento destas. A prevenção ou o alívio dos sintomas é um dos aspectos importantes na assistência pré-natal. Diante 
do seu surgimento, a adoção de intervenções de enfermagem neste contexto possibilita uma melhora na qualidade de vida dessas mulheres ${ }^{(9)}$.

Entre as manifestações que podem ser apresentadas por gestantes estão náuseas, vômitos e tonturas, pirose, eructação/plenitude gástrica, sialorreia, fraquezas e desmaios, dor abdominal, cólicas, flatulência e obstipação intestinal, queixas urinárias, falta de ar, mastalgia, dor lombar e edema, entre outras.

As náuseas e vômitos acometem cerca de 50 a $80 \%$ das gestantes e, geralmente, terminam por volta da $16^{\mathrm{a}}$ a $20^{a}$ semana. Podem aparecer em qualquer hora do dia, sendo mais comum pela manhã, ao levantar-se. $O$ fator desencadeante deste distúrbio ainda não foi elucidado, mas acredita-se que esteja associado ao aumento da gonadotrofina coriônica humana e estrogênio, além da redução da acidez do estômago, do tônus e da motilidade do trato gastrointestinal ${ }^{(10)}$.

Esta sintomatologia representa um dos grandes incômodos na gravidez tendo importante repercussão na diminuição da qualidade de vida e do bem-estar do binômio mãe-filho. As intervenções de enfermagem que devem ser adotadas são explicar que são sintomas comuns do início da gestação; orientar a mulher para alimentação fracionada (seis refeições por dia), evitar frituras, gorduras e alimentos muito condimentados; evitar líquidos durante as refeições, dando preferência à ingestão nos intervalos; agendar consulta médica para avaliar a necessidade de usar medicamentos ou referir ao pré-natal de alto risco, em caso de vômitos frequentes; e orientar a mulher a comer uma bolacha de água e sal antes de se levantar ${ }^{(7)}$.

O surgimento do edema está associada à resistência em que o sangue encontra para retornar aos membros superiores, o que leva ao aumento do extravasamento de líquidos nos interstícios celulares mais comumente nos inferiores.

Entre as intervenções de enfermagem para a prevenção ou diminuição do edema estão não permanecer muito tempo em pé ou sentada; repousar (cerca de 20 minutos) várias vezes ao dia, com as pernas elevadas ao nível do coração; não usar roupas muito justas e, se possível, utilizar meia-calça elástica; fazer com os pés movimentos circulares para melhorar a circulação; e orientar a paciente que, ao deitar, prefira o decúbito lateral esquerdo, descomprimindo temporariamente a veia cava inferior e proporcionando melhor retorno venoso ao coração ${ }^{(7)}$.

Na gestação, acontece uma sequência de mudanças no corpo da mulher, seu útero está em constante cresci- mento, formando um abdome protruso. Há o deslocamento de seu centro de gravidade, além da liberação de hormônios, como estrógeno e relaxina, que ocasionam crescente afrouxamento dos ligamentos. O objetivo dessas alterações consiste em aumentar o tamanho da cavidade pélvica e tornar o parto mais fácil. Todas essas modificações causam lordose, fazendo com que ela sobrecarregue os músculos lombares e posteriores da coxa, gerando um processo doloroso, denominado de lombalgia ${ }^{(11)}$.

A lombalgia é comum no último trimestre da gestação podendo levar à fadiga, alterações no padrão do sono, incapacidade motora e depressão (em decorrência da dor ser um fator que provoca alterações de humor). Por isso, deve ser uma das preocupações do enfermeiro durante o pré-natal ${ }^{(12)}$.

As intervenções de enfermagem a este distúrbio são correção de postura ao sentar-se e ao andar; uso de sapatos com saltos baixos e confortáveis; aplicação de calor local; eventualmente, usar analgésico (se não for contraindicado) por tempo limitado; dormir pelo menos 8 horas por dia, em colchão confortável; e assegurar às mulheres que o problema geralmente se resolve espontaneamente após o nascimento ${ }^{(7)}$.

O crescimento uterino e o aumento da produção da progesterona levam os pulmões a funcionarem de forma diferente ${ }^{(7)}$. O crescimento contínuo do útero comprime o diafragma aumentando sua atividade; há também aumento de 5 a $7,5 \mathrm{~cm}$ da cavidade torácica. Todas essas alterações tornam a respiração da mulher mais diafragmática que abdominal, podendo ocasionar dispneia. Além disso, a gestante respira mais rápido porque tem necessidade de mais oxigênio para si e para o feto ${ }^{(13)}$.

As intervenções que devem ser adotadas mediante o surgimento de dispneia são explicar à mulher que a dificuldade de respirar é normal durante a gestação, principalmente no último trimestre; orientar para elevar a cabeceira do leito ao deitar; e deitar em decúbito lateral esquerdo, o que deslocará o útero da veia cava inferior e melhorará a respiração ${ }^{(7)}$.

Percebe-se, através dos depoimentos, que as orientações prestadas pelo enfermeiro na assistência pré-natal de baixo risco foram adequadas e possibilitaram a compreensão, por parte das gestantes, da sintomatologia apresentada, sendo indicadas intervenções pertinentes para cada manifestação; contudo, nem todas as intervenções possíveis foram recomendadas às gestantes.

Portanto, as intervenções de enfermagem surgem neste contexto para efetivar a sistematização da assistência e melhorar a qualidade de vida, já que durante este período a mulher passa por alterações em todos os 
âmbitos, que por vezes traduzem-se em sinais e sintomas desagradáveis para a mulher e, consequentemente, afetando seu bem estar ${ }^{(7)}$.

\section{CONSIDERAÇÕES FINAIS}

Este estudo buscou analisar as orientações de enfermagem fornecidas às gestantes no que se refere às queixas clínicas mais frequentes durante a gravidez em uma Unidade Básica de Saúde. Foi identificado que as orientações de enfermagem fornecidas pelo enfermeiro durante o pré-natal contribuíram para o alívio dos sintomas apresentados e possibilitaram a compreensão parcial da sintomatologia por parte das gestantes.

Dessa forma, faz-se necessário sensibilizar os profissionais de enfermagem que realizam as consultas de pré-natal sobre a importância de esclarecer e orientar as gestantes sobre as alterações fisiológicas no período gestacional, a fim de que este período seja vivenciado da forma mais tênue possível, objetivando a diminuição dos níveis de ansiedade e temor que geralmente ocorrem nesses momentos. Recomenda-se, ainda que as orientações oferecidas às gestantes sobre as queixas clínicas mais frequentes na gravidez sejam disponibilizadas também de forma escrita para que sejam melhor compreendidas.

Portanto, o papel do enfermeiro neste sentido visa a programar medidas cabíveis para cada desconforto provocado pela adaptação e efetivar essas condutas nas suas peculiaridades, de forma a aumentar o bem estar do binômio mãe-filho.

Assim, ao término deste estudo, percebe-se que os objetivos inicialmente propostos foram atingidos e espera-se que o mesmo contribua para a melhoria da práxis dos enfermeiros, permitindo reflexões sobre a importância do seu papel de educador no contexto da saúde.

\section{REFERÊNCIAS}

1. Ferreira CHJ, Nakano AMS. Reflexões sobre as bases conceituais que fundamentam a construção do conhecimento acerca da lombalgia na gestação. Rev. Latino-Am. Enfermagem 2001;9(3) [acesso em 22 ago 2012]. Disponível: http://dx.doi.org/10.1590/S010411692001000300015.

2. Reberte LM, Hoga LAK. O desenvolvimento de um grupo de gestantes com a utilização da abordagem corporal. Texto Contexto Enferm. 2005;14(2) [acesso em 22 ago 2012]. Disponível: http://dx.doi.org/10.1590/S01040707200500020000.
3. Silva PSR. Tratamento de náuseas e vômitos na grávida por pressão periódica num ponto de acupuntura [dissertação]. Covilhã: Universidade da Beira Interior; 2008.

4. Shimizu HE, Lima MG. As dimensões do cuidado prénatal na consulta de enfermagem. Rev. bras enferm. 2009;62(3) [acesso em 22 ago 2013]. Disponível: http:// dx.doi.org/10.1590/S0034-71672009000300009.

5. Barbosa TL, Gomes LMX, Dias OV. O pré-natal realizado pelo enfermeiro: satisfação das gestantes. Cogitare enferm. 2011;16(1) [acesso em 22 ago 2013]. Disponível: http://ojs.c3sl.ufpr.br/ojs2/index.php/ cogitare/article/view/21108/13934.

6. Minayo MCS. O desafio do conhecimento: pesquisa qualitativa em saúde. $7^{\text {a }}$ ed. São Paulo: Hucitec; 2000.

7. Oliveira GKS, França BF, Freire KRB, Oliveira ER. Intervenções de enfermagem nas adaptações fisiológicas da gestação. Veredas Favip. 2010;3(1):58-67.

8. São Paulo (Estado). Secretaria de Saúde. Atenção à gestante e à puérpera no SUS-SP: manual técnico do pré-natal e puerpério. São Paulo; 2010.

9. Enkin M. Guia para atenção efetiva na gravidez e no parto. $3^{\mathrm{a}}$ ed. Rio de Janeiro: Guanabara Koogan; 2005.

10. Carrara HA, Duarte G. Semiologia obstétrica. Ribeirão Preto: USP; 1996.

11. Novaes FS, Shimo AKK, Lopes MHBM. Lombalgia na gestação. Rev. Latino-Am. Enfermagem 2006;14(4) [acesso em 22 ago 2013]. Disponível: http://www.scielo. br/pdf/rlae/v14n4/v14n4a22.pdf. (Não encontrei o DOI)

12. Rezende MF. Obstetrícia fundamental. $11^{\mathrm{a}}$ ed. Rio de Janeiro: Guanabara Koogan; 2007.

13. Ricci SS. Enfermagem materno-neonatal e saúde da mulher. $1^{\mathrm{a}}$ ed. Rio de Janeiro: Guanabara Koogan; 2008. 